\title{
Risk Management in the Construction of Intelligent Transportation Platform Based on Artificial Intelligence
}

\author{
Hongxi Di $\mathbf{i}^{1,2,3,4^{*}}$ \\ ${ }^{I} X i$ 'an University of Science and Technology, College of Management, Xi'an, Shaanxi, 710054, China \\ ${ }^{2}$ Univ Sci \& Technol China, Sch Management, Hefei 230026, China \\ ${ }^{3}$ Energy Economy and Management Research Center, Xi' an University of Science and Technology, Xi'an, \\ Shaanxi, 710054, China \\ ${ }^{4}$ HeNan Newvid Technology Co., Ltd, Luoyang, Henan, 471000, China \\ *Corresponding Author.
}

\begin{abstract}
The smoothness of a city's traffic is one of the signs that measure the development of a city. With the advent of the era of artificial intelligence and big data, the previously bloated and blocked motor vehicle transportation system is increasingly unable to adapt to this fast-paced society. The use of artificial intelligence technology to build a brand-new intelligent transportation platform is imminent, and reasonable planning of the risks in the construction of the transportation platform can effectively increase the transmission rate and reduce the frequency of accidents. The purpose of this paper is to study the risk management in the construction of intelligent transportation platform based on artificial intelligence. This article first summarizes the basic theory of artificial intelligence, and then extends the core technology of artificial intelligence. And combined with the current situation of my country's contemporary intelligent transportation, analysis of the existing problems and shortcomings, on this basis, combined with artificial intelligence technology to research and analyze the risk management in the construction of intelligent transportation platform. This research systematically expounds the risk construction principles, model construction and risk response measures of the intelligent transportation platform. This paper uses field surveys, interviews and other research methods to research and investigate traffic risk management in a certain place. The experimental research shows that risk management in the construction of intelligent transportation platforms based on artificial intelligence has higher feasibility than traditional traffic management.
\end{abstract}

Keywords: Risk Management, Intelligent Transportation Platform, Traffic safety, Artificial Intelligence

\section{Introduction}

With the reform and opening up, my country's economy has continued to develop, and the people's living standards have continued to increase. With this, the traffic in urban areas has become increasingly congested [1-2]. In addition, plane mixed traffic is currently the mainstream traffic mode commonly used in large cities in my country, and it is difficult for this traffic mode to improve the effect of transportation efficiency [3-4].

In order to solve the traffic problem, the United States is competing to invest a lot of money and manpower, and began to conduct large-scale research experiments on the intelligentization of road transportation [5-6]. The US federal government's annual budget for ITS (intelligent transportation system) research and development from 1990 to 1997 totaled US $\$ 1.2935$ million [7-8]. In addition, emerging industrial countries and developing countries have also begun the comprehensive development and research of ITS. For example, Singapore has begun to implement non-stop electronic toll collection throughout the country [9-10].

This article aims to improve the risk management of the intelligent transportation platform, and aims to study the

ISSN: 0010-8189

(c) CONVERTER 2020

www.converter-magazine.info 
risk management in the construction of the intelligent transportation platform based on artificial intelligence, by combining the traditional traffic risk management with the risk management in the construction of the intelligent transportation platform based on artificial intelligence.

\section{Application Research on Risk Management in the Construction of Intelligent Transportation Platform Based on Artificial Intelligence}

\subsection{Artificial Intelligence Technology}

Artificial intelligence is a technical science that studies and develops theories, methods, technologies, and application systems used to simulate, extend, and expand human intelligence. It is a branch of computer science and a frontier field of computer science and technology. It can be said that it is an interdisciplinary subject [11-12].

\subsection{Analysis of Intelligent Transportation Platform Construction}

2.2.1 Function analysis

1) Real-time feedback to the public security department via the Internet of the key public security vehicles (blacklisted vehicles) found in the road network operation information;

2)Realize the interface docking with the traffic police's public security management system, and obtain the alarm information of the stolen vehicle from the buckle base station in real time.

3) Realize information synchronization accurate to the minute, while supporting manual query.

\subsubsection{Structural analysis}

The intelligent transportation platform is composed of five subsystems: network communication system, traffic management system, traffic command center, traffic management business information system, and command and dispatch system;

1) Network communication system

With the continuous improvement of network scale and broadband speed, the traffic management information system has gradually evolved into a network communication system support platform that can realize the sharing of multiple services and the coexistence of multiple communication methods. The business data related to traffic management in Xi'an is mainly provided by the public security private network, wireless border access platform, border access platform, signal control subnet and network security subsystem, so as to realize the safe exchange and transmission of data.

2) Traffic management business information system

The system covers all business of traffic management, including driver/vehicle management module, traffic accident management module, traffic violation management module, wireless police system and bank reconciliation system.

\section{3) Command and dispatch system}

The command and dispatch system consists of three parts: the police force GPS positioning system, $350 \mathrm{M}$ voice dispatch system and 122 police response system, which can deploy police force in time according to the alarm situation or the commander's order for traffic congestion, traffic accidents and other situations.

\subsection{Risk Assessment Analysis of Intelligent Transportation Platform Construction Projects}

2.3.1 Principle analysis

1) Purpose principle

ISSN: 0010-8189

(c) CONVERTER 2020

www.converter-magazine.info 
The principle of purpose is the most basic principle for the construction of the risk assessment index system. The entire risk index system should be carried out around the goal of assessing and quantifying the risks of the intelligent transportation platform construction project, and is composed of typical indicators that reflect the key elements of the intelligent transportation platform construction project risk. It is necessary to objectively, truthfully, scientifically, reasonably and as comprehensively as possible to reflect various risk factors affecting the construction of intelligent transportation platform projects.

2) The principle of systematic comprehensiveness

The design of the project risk factor index system should also conform to the system theory point of view, be systematic and comprehensive, and be able to comprehensively and systematically reflect the important risks that may arise in the construction of the intelligent transportation platform project from all angles and different levels, rather than focusing on a single or certain several important risks.

\subsection{Project Risk Assessment}

\subsubsection{Fuzzy Analytic Hierarchy Process}

Based on the analytic hierarchy process, this paper uses a fuzzy consistency matrix method to construct the risk evaluation model of the intelligent transportation platform construction project. At the same time, considering that there are many factors involved in the risk of this project, the fuzzy analytic hierarchy process can decompose the project risk into a hierarchical structure in an orderly manner, and use the fuzzy judgment matrix to display the project in a simple pairwise comparison.

The calculation steps of fuzzy analytic hierarchy process:

Step 1: Build a hierarchical analysis structure of risk factors

Step 2: Establish a fuzzy judgment matrix

The analytic hierarchy model can reflect the affiliation between the upper and lower levels. The next step is to establish a fuzzy judgment matrix between the factors of each level based on the analytic hierarchy model and the collected expert judgment opinions. This article does not use the method of quantification of triangular fuzzy numbers to compare the factors, but uses the quantitative method of importance in the analytic hierarchy process to construct the fuzzy judgment matrix.

Step 3: consistency check

The fuzzy matrix has the following properties: for the fuzzy matrix $A=\left(a_{i j}\right)_{n^{*} n}$, after summing it by rows, the fuzzy consistency matrix $\mathrm{T}=\left(\mathrm{t}_{\mathrm{ij}}\right)_{\mathrm{n}{ }_{\mathrm{n}}}$ can be obtained, where

$$
t_{i j}=\frac{t_{i}-t_{j}}{n-1} \times \frac{1}{2}+\frac{1}{2}
$$

Step 4: Determine the weight values of elements $b_{1}, b_{2}, \ldots, b_{n}$

From the third step, we can see that the fuzzy consistency matrix of b1, b2, .., bn is $A=\left(a_{i j}\right)_{n} *_{n}$, and the weight values of $b_{1}, b_{2}, \ldots, b_{n}$ are $k_{1}, k_{2}, \ldots, k_{n}$, and the fuzzy consistency matrix is $A=\left(a_{i j}\right)_{n * n}$. The properties of the matrix can be seen

$$
b_{i j}=b\left(k_{i}-k_{j}\right)+\frac{1}{2}
$$

When the fuzzy judgment matrix A is not consistent, establish constraint conditions:

$$
\sum_{i}^{n} k_{i}=1, k_{i} \geq 0
$$

ISSN: 0010-8189

(c) CONVERTER 2020

www.converter-magazine.info 


$$
\begin{gathered}
\min \sigma=\sum_{i}^{n} \sum_{j}^{n}\left(b_{i j}=b\left(k_{i}-k_{j}\right)+\frac{1}{2}\right)^{2} \\
\min (k, r)=\sum_{i}^{n} \min \sigma=\sum_{i}^{n} \sum_{j}^{n}\left(b_{i j}=b\left(k_{i}-k_{j}\right)+\frac{1}{2}\right)^{2}+2 r\left(\sum_{i}^{n} k_{i}-1\right) \\
\sum_{i}^{n} r_{i}+2 b\left(k_{i}-k_{j}\right)+\left(b_{i}-b_{j}\right)
\end{gathered}
$$

According to the above formula, the ranking of the weights can be calculated: $\mathrm{k}=\left(\mathrm{k}_{1}, \mathrm{k}_{2}, \mathrm{k}_{3} \ldots \ldots, \mathrm{k}_{\mathrm{n}}\right)^{\mathrm{T}}$, so as to get the ranking of the importance of all risk factors.

2.4.2 Using fuzzy analytic hierarchy process to calculate the weight of risk evaluation index of intelligent transportation platform construction project:

STEP1: build the project risk evaluation index system, get the hierarchical structure of the model, divide the evaluation index into 5 first-level indexes and 14 second-level indexes, so set $\mathrm{A}$ as the wind evaluation index for the intelligent transportation platform construction project, and B1-B5 as The first-level indicators, C1-C14 are the second-level indicators attached to B1-B5. Various indicators have a subordination relationship, and the C-level indicators are subordinate to the B-level indicators.

STEP2: Use the expert scoring method to evaluate each indicator factor in pairs. First, experts from the practical and theoretical circles in the industry are invited to form an expert team. The team includes 5 experienced software engineering project managers, 3 university scholars, and $2 \mathrm{~A}$ traffic engineering planner; then anonymously ask the experts for index scores (1-10 scoring method), and perform statistical analysis on the experts' scoring results, and feed back the statistical results to the experts.

STEP3: Calculate the weight of each level, use the formula to solve the weight of the fuzzy complementary judgment matrix, and get the weight vector of the B-level index.

\section{Experimental Research on Risk Management in the Construction of Intelligent Transportation Platform Based on Artificial Intelligence}

\subsection{Subjects}

(1) In order to make this experiment more scientific and effective, this experiment compares the risk management of traditional transportation platform with the risk management in the construction of intelligent transportation platform based on artificial intelligence. The platform system and the intelligent transportation platform risk management system based on artificial intelligence use the same data set for efficiency testing. Use the analytic hierarchy process to analyze and research the obtained data.

(2) In order to further conduct experimental research and analysis on the construction of intelligent transportation platform based on artificial intelligence, this experiment analyzes the risk management performance in the construction of intelligent transportation platform based on artificial intelligence through network interviews. The targets are 12 university professors of traffic engineering in a university in a certain place, and 14 front-line dispatchers of the vehicle management office. Among them, the male to female ratio is roughly two to one to ensure the scientific nature of the experimental data.

3.2 Research Methods

ISSN: 0010-8189

(c) CONVERTER 2020

www.converter-magazine.info 
3.2.1 Field research method

This experiment conducted a survey and collected data on a certain local peak road section. These data provide a reliable reference for the final research results of this article.

\subsubsection{Interview method}

This research uses network interviews with college transportation professors, job dispatchers of vehicle management offices and records interview data. These data not only provide theoretical support for the topic selection of this article, but also provide data support for the final research results of this article.

\subsubsection{Mathematical statistics}

Use related software to analyze and count the research data.

\section{Experimental Analysis of Risk Management in the Construction of an Artificial Intelligence-Based Intelligent Transportation Platform}

\subsection{Comparative Analysis of Intelligent Transportation Risk Management Systems}

In order to make this experiment more scientific and effective, this experiment compares and analyzes the risk management in the construction of the traditional intelligent transportation risk management system and the intelligent transportation platform based on artificial intelligence. The data results obtained are shown in Table 1.

Table1. Comparative Analysis of Intelligent Transportation Risk Management System

\begin{tabular}{|c|c|c|c|c|}
\hline & $\begin{array}{c}\text { Traffic } \\
\text { management }\end{array}$ & Traffic command & Traffic dispatch & Others \\
\hline A I & $71.3 \%$ & $74.2 \%$ & $69.4 \%$ & $64.8 \%$ \\
\hline Traditional & $50.7 \%$ & $55.2 \%$ & $54.7 \%$ & $51.2 \%$ \\
\hline
\end{tabular}

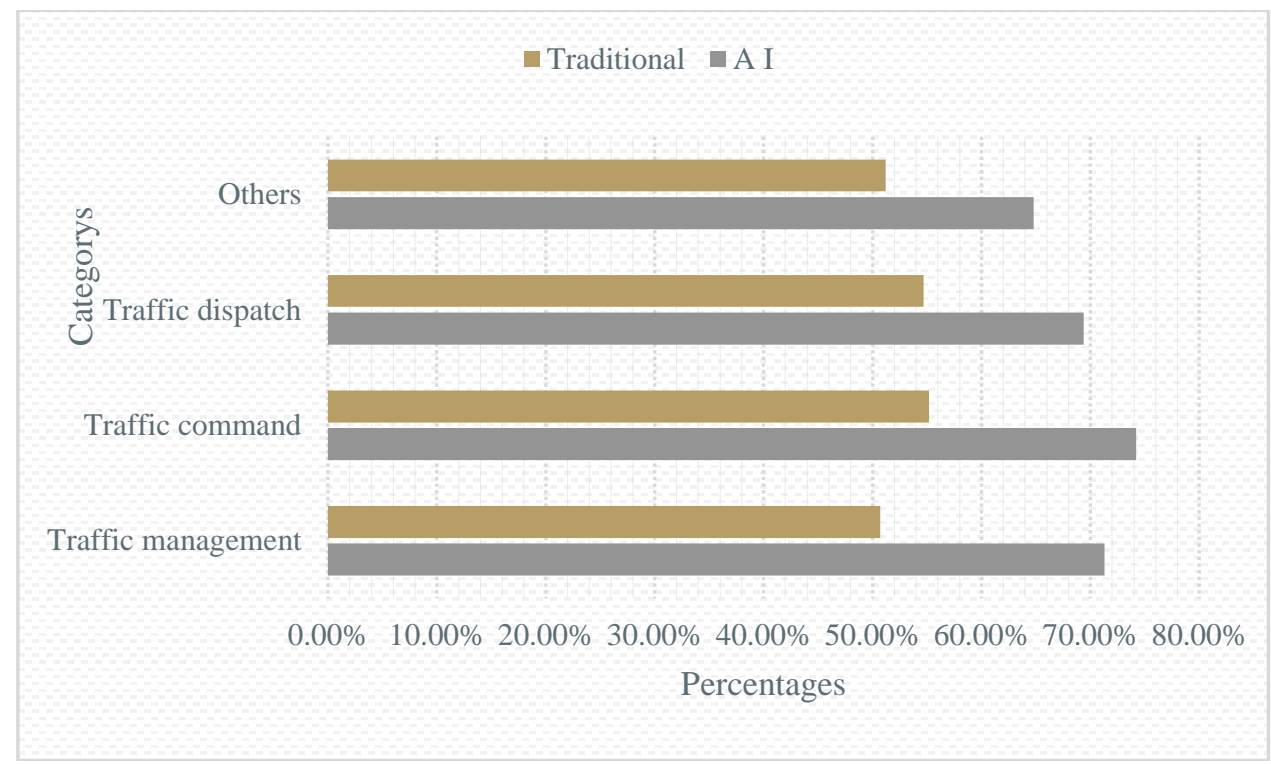

Figure 1. Comparative Analysis of Intelligent Transportation Risk Management System

It can be seen from Figure 1 that compared to the traditional risk management of transportation platforms, the risk management system in the construction of intelligent transportation platforms based on artificial intelligence has higher risk management efficiency in each module part, especially the traffic command module is more than $20 \%$ higher, which fully reflects the feasibility of risk management in the construction of an artificial intelligence-based ISSN: 0010-8189

(c) CONVERTER 2020 
intelligent transportation platform.

\subsection{Performance Analysis of Intelligent Transportation Platform Construction Based on Artificial Intelligence}

In order to further research and analyze the risk management of intelligent transportation platform construction based on artificial intelligence, this experiment analyzed the risks of intelligent transportation platform based on artificial intelligence on the basis of network access to relevant traffic engineering professors and front-line traffic command and dispatch personnel. The ten-point scoring system is used this time, and the data obtained is shown in Table 2 .

Table2. Analysis of risk management performance of intelligent transportation platform construction based on artificial intelligence

\begin{tabular}{|c|c|c|c|c|}
\hline & Convenience & compatibility & Robustness & Others \\
\hline 1 & 10 & 8 & 7 & 5 \\
\hline 2 & 8 & 8 & 8 & 5 \\
\hline 3 & 9 & 5 & 10 & 5 \\
\hline 4 & 7 & 7 & 7 & 6 \\
\hline 5 & 7 & 7 & 8 & 7 \\
\hline 6 & 6 & 8 & 8 & 4 \\
\hline 7 & 5 & 8 & 7 & 5 \\
\hline 8 & 7 & 9 & 6 & 5 \\
\hline$\ldots$ & & & 5 & \\
\hline
\end{tabular}

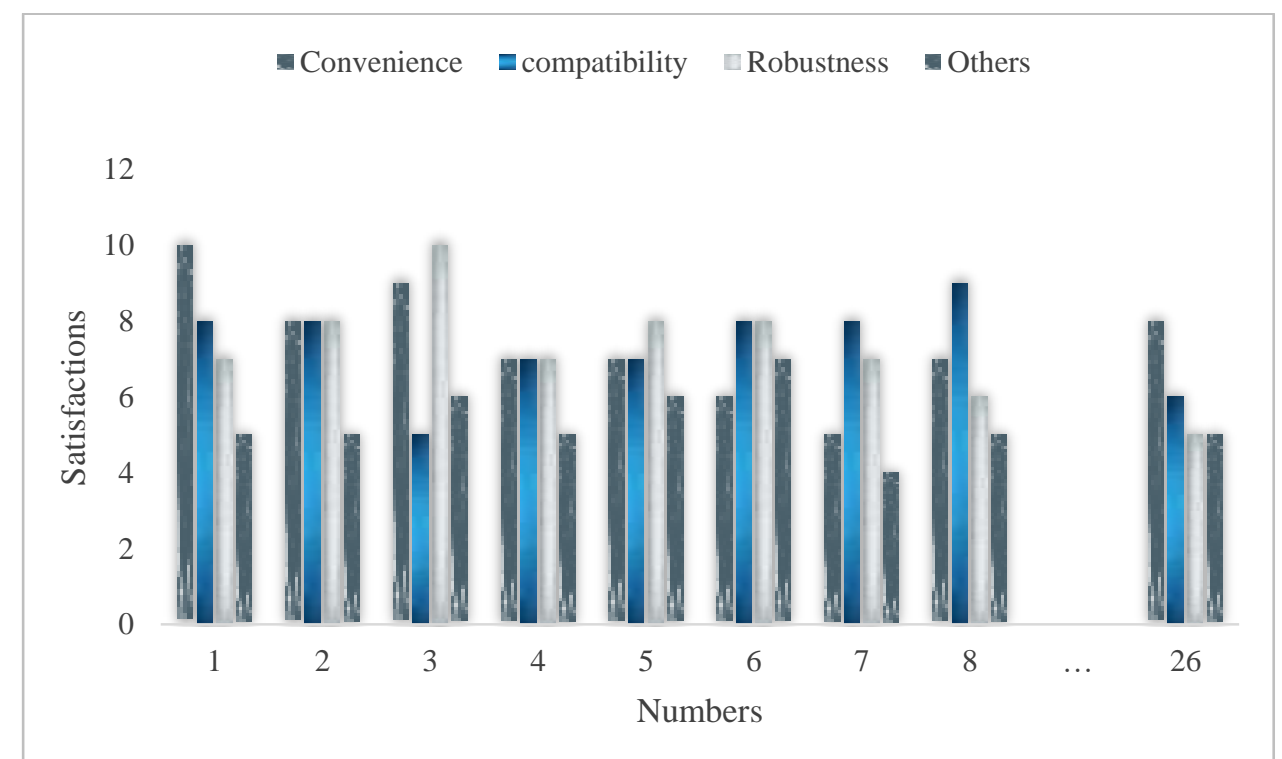

Figure2. Analysis of risk management performance of intelligent transportation platform construction based on artificial intelligence

It can be seen from Figure 2 that most traffic engineering professors and traffic mobilizers agree with the intelligent transportation platform based on artificial intelligence, especially the convenient operation of the intelligent transportation platform based on artificial intelligence, which is recognized by most people. The side reflects that the problems existing in the construction of my country's current transportation platform need to be solved urgently.

ISSN: 0010-8189

(c) CONVERTER 2020 


\section{Conclusion}

The increase in the number of urban motor vehicles has brought major challenges to the smooth operation of the urban transportation system. A series of problems such as traffic congestion and the high incidence of traffic accidents have restricted the quality of urban life. The intelligent transportation system integrates information technology, information acquisition technology, information transmission technology, mobile data communication technology into the entire traffic management system. Through reasonable guidance and dispatch, existing traffic facilities can be effectively used to reduce traffic load and environmental pollution. Ensuring traffic safety has become the main development direction of various countries to solve urban traffic problems.

\section{Acknowledgements}

This study was supported by the Scientific research plan projects of Education Department of Shaanxi (18JK0487), the Philosophy and Social Science Prosperity Program of Xi' an University of Science and Technology (2018SY08, 20180014), the PhD early development program of Xi'an University of Science and Technology(2017QDJ050).

\section{References}

[1] N. Shaukat, B. Khan, S. M. Ali, et al., "A survey on electric vehicle transportation within smart grid system,” Renewable \& Sustainable Energy Reviews, vol. 81, no. 1, pp. 1329-1349, 2017.

[2] S. Siuhi, J. Mwakalonge, "Opportunities and challenges of smart mobile applications in transportation," Journal of Traffic \& Transportation Engineering, vol. 2016, no. 06, pp. 96-106.

[3] B.Y. Chen, W. Lam, "Special issue: Smart transportation: Theory and practice," Journal of advanced transportation, vol. 50, no. 2, pp. 141-144, 2016.

[4] Y. Wei, Y. Wang, Y. Chang, et al., "Research on the construction of "u-smart transportation system" under Artificial Intelligence technology,” IOP Conference Series Materials Science and Engineering, vol. 490, no. 4, pp. 042002, 2019.

[5] K. Xu, F.F. Yang, Z.Y. He, et al., "Cultivation of Compound Graduates of Computer Science and Smart Transportation," Laboratory Research and Exploration, vol. 038, no. (006), pp. 171-175, 2019.

[6] Y. Liu, X. Weng, J. Wan, et al., "Exploring Data Validity in Transportation Systems for Smart Cities," IEEE Communications Magazine, vol. 55, no. 5, pp. 26-33, 2017.

[7] J. Lin, W. Yu, X. Yang, et al., "An Edge Computing Based Public Vehicle System for Smart Transportation," IEEE Transactions on Vehicular Technology, vol. 69, no. 11, pp.12635-12651, 2020.

[8] L.A. Schintler, C.L. Mcneely, "Mobilizing a Culture of Health in the Era of Smart Transportation and Automation," World Medical and Health Policy, vol. 12, no. 2, pp.137-162, 2020.

[9] “Government and governance in intelligent cities, smart transportation study case in Bogotá Colombia," Ain Shams Engineering Journal, vol. 11, no. 1, pp. 25-34, 2020.

[10] B.E. Bilgin, S. Baktir, V.C. Gungor, "Collecting smart meter data via public transportation buses," Iet Intelligent Transport Systems, vol. 10, no. 8, pp. 515-523, 2016.

[11] B. Jan, H. Farman, M. Khan, et al., "Designing a Smart Transportation System: An Internet of Things and Big Data Approach,” IEEE Wireless Communications, vol. 26, no. 4, pp. 73-79, 2019.

[12] M. Humayun, N.Z. Jhanjhi, B. Hamid, et al., "Emerging Smart Logistics and Transportation Using IoT and Blockchain,” IEEE Internet of Things Magazine, vol. 3, no. 2, pp. 58-62, 2020.

ISSN: 0010-8189

(c) CONVERTER 2020 